\title{
Kinetics of Solid-State Reactive Diffusion in the (Pd-Cr)/Sn System
}

\author{
Masaki Hashiba*1, Koji Masui*1 and Masanori Kajihara*2 \\ Department of Materials Science and Engineering, Tokyo Institute of Technology, Yokohama 226-8502, Japan
}

The growth of compounds during energization heating at the interconnection between a Sn-based solder and a multilayer $\mathrm{Pd} / \mathrm{Ni} / \mathrm{Cu}$ conductor may be inhibited by alloying of $\mathrm{Pd}$ with $\mathrm{Cr}$. To examine such influence of $\mathrm{Cr}$ on the compound growth, the kinetics of solid-state reactive diffusion in the $(\mathrm{Pd}-\mathrm{Cr}) / \mathrm{Sn}$ system was experimentally determined in the present study. Experiments were conducted using $\mathrm{Sn} /(\mathrm{Pd}-$ $\mathrm{Cr}$ )/Sn diffusion couples with $\mathrm{Cr}$ mol fractions of $y=0.110,0.215$ and 0.323 which were prepared by a diffusion bonding technique. The diffusion couples were isothermally annealed in the temperature range of $T=433-473 \mathrm{~K}$ for various times up to $t=360 \mathrm{~h}$. During annealing, a compound layer consisting of different matrices and lamellar phases is formed at the original ( $\mathrm{Pd}-\mathrm{Cr}) / \mathrm{Sn}$ interface in the diffusion couple. From the $\mathrm{Pd}-\mathrm{Cr}$ side to the $\mathrm{Sn}$ side in the compound layer, the matrices are $\mathrm{PdSn}_{2}, \mathrm{PdSn}_{3}$ and $\mathrm{PdSn}_{4}$, and the lamellar phases are $\left(\mathrm{Cr}_{0.9} \mathrm{Pd}_{0.1}\right)_{3} \mathrm{Sn}_{\text {, }}$ $\left(\mathrm{Cr}_{0.95} \mathrm{Pd}_{0.05}\right)_{2} \mathrm{Sn},\left(\mathrm{Cr}_{0.9} \mathrm{Pd}_{0.1}\right) \mathrm{Sn}$ and $\mathrm{CrSn}_{2}$. The total thickness of the compound layer is proportional to a power function of the annealing time. The exponent $n$ of the power function is rather close to 0.5 independent of $y$ at $T=453-473 \mathrm{~K}$. At $T=433 \mathrm{~K}$, however, $n \cong 0.5$ for $y=0-$ 0.110 , but $n=0.7-0.8$ for $y=0.215-0.323$. Thus, the overall compound growth is controlled by volume diffusion for $y=0-0.323$ at $T=453-$ $473 \mathrm{~K}$ and for $y=0-0.110$ at $T=433 \mathrm{~K}$. On the other hand, for $y=0.215-0.323$ at $T=433 \mathrm{~K}$, the interface reaction at the moving interface contributes to the rate-controlling process. The overall growth rate of the compound layer is insensitive to $y$ at $y<y_{\mathrm{c}}$ but monotonically decreases with increasing value of $y$ at $y>y_{\mathrm{c}}$, where $y_{\mathrm{c}}=0.1$ and 0.2 at $T=433-453 \mathrm{~K}$ and $473 \mathrm{~K}$, respectively. Consequently, the compound growth is actually decelerated by the addition of $\mathrm{Cr}$ with $y>0.2$ into $\mathrm{Pd}$ in the multilayer $\mathrm{Pd} / \mathrm{Ni} / \mathrm{Cu}$ conductor [doi:10.2320/matertrans.M2014202]

(Received May 30, 2014; Accepted October 14, 2014; Published December 5, 2014)

Keywords: metallization, solder, conductor, intermetallics

\section{Introduction}

Copper-based alloys are widely used as conductor materials in the electronics industry due to high electrical conductivity. If the $\mathrm{Cu}$-based conductor is interconnected using a $\mathrm{Sn}$-based solder, $\mathrm{Cu}_{6} \mathrm{Sn}_{5}$ and $\mathrm{Cu}_{3} \mathrm{Sn}$ are formed at the interconnection between the conductor and the solder during soldering and then gradually grow during energization heating at solid-state temperatures. ${ }^{1-11)}$ Since the $\mathrm{Cu}-\mathrm{Sn}$ compounds are brittle and possess high electrical resistivities, their growth deteriorates the mechanical and electrical properties of the interconnection. To suppress $\mathrm{Cu}-\mathrm{Sn}$ compound formation, the $\mathrm{Cu}$-based conductor is generally plated with a $\mathrm{Ni}$ layer. However, $\mathrm{Ni}$ is not sufficiently corrosion resistant. Thus, the Ni layer is plated with a $\mathrm{Au}$ or Pd layer to improve corrosion resistance. ${ }^{12-15)}$

The reactive diffusion in the $\mathrm{Pd} / \mathrm{Sn}$ system was experimentally examined at solid-state temperatures using $\mathrm{Sn} / \mathrm{Pd} /$ $\mathrm{Sn}$ diffusion couples prepared by a diffusion bonding technique in a previous study. ${ }^{16)}$ In this experiment, the diffusion couples were isothermally annealed at temperatures of $T=433-473 \mathrm{~K}$. At the $\mathrm{Pd} / \mathrm{Sn}$ interface in the diffusion couple, $\mathrm{PdSn}_{4}, \mathrm{PdSn}_{3}$ and $\mathrm{PdSn}_{2}$ layers are formed at $T=433 \mathrm{~K}$, but only $\mathrm{PdSn}_{4}$ and $\mathrm{PdSn}_{3}$ layers are produced at $T=453 \mathrm{~K}$ and $473 \mathrm{~K}$. In this case, the total thickness of the compound layers is proportional to the square root of the annealing time. Such a relationship is called the parabolic relationship. Furthermore, grain growth occurs in the compound layers. As a consequence, the layer growth is controlled by volume diffusion. ${ }^{17)}$ At $T=433-473 \mathrm{~K}$, however, the overall growth rate of the compound layers is one order of magnitude greater for the reactive diffusion in the $\mathrm{Pd} / \mathrm{Sn}$ system $^{16)}$ than for that in the $\mathrm{Cu} / \mathrm{Sn}$ system. ${ }^{11)}$

\footnotetext{
${ }^{* 1}$ Graduate Student, Tokyo Institute of Technology

${ }^{* 2}$ Corresponding author, E-mail: kajihara@materia.titech.ac.jp
}

Hence, the $\mathrm{Pd}$ layer of the multilayer $\mathrm{Pd} / \mathrm{Ni} / \mathrm{Cu}$ conductor accelerates the deterioration of the interconnection during solid-state energization heating.

The effect of Ag on the solid-state reactive diffusion in the $\mathrm{Pd} / \mathrm{Sn}$ system was experimentally examined in previous studies. ${ }^{18,19)}$ In these experiments, $\mathrm{Sn} /(\mathrm{Pd}-\mathrm{Ag}) / \mathrm{Sn}$ diffusion couples with $\mathrm{Ag}$ concentrations of $y=0.25-0.75$ were isothermally annealed at $T=433-473 \mathrm{~K}$, where $y$ stands for the mol fraction of $\mathrm{Ag}$. As to $y=0.25-0.50,{ }^{18)} \mathrm{a} \mathrm{PdSn}_{4}$ layer dispersed with fine $\mathrm{Ag}_{3} \mathrm{Sn}$ particles is predominantly formed at the $(\mathrm{Pd}-\mathrm{Ag}) / \mathrm{Sn}$ interface in the diffusion couple during annealing. On the other hand, for $y=0.75,{ }^{19)}$ a compound layer composed of $\mathrm{PdSn}_{4}$ and $\mathrm{Ag}_{3} \mathrm{Sn}$ lamellae is produced at the interface. Like the Pd/Sn system, the parabolic relationship holds between the thickness of the compound layer and the annealing time also in the $(\mathrm{Pd}-\mathrm{Ag}) / \mathrm{Sn}$ system. Here, the notation $(\mathrm{A}-\mathrm{B}) / \mathrm{C}$ means that reactive diffusion occurs between a binary A-B alloy and a pure $\mathrm{C}$ metal. As the Ag concentration $y$ increases, the parabolic coefficient decreases slightly at $y<0.5$ but remarkably at $y>0.5$. Therefore, the growth of compounds at the interconnection between the Sn-based solder and the multilayer $\mathrm{Pd} / \mathrm{Ni} / \mathrm{Cu}$ conductor is effectively inhibited by addition of $\mathrm{Ag}$ with $y>0.5$ into $\mathrm{Pd}$.

According to a recent phase diagram in the binary $\mathrm{Pd}-\mathrm{Cr}$ system, ${ }^{20)}$ the solubility of $\mathrm{Cr}$ in $\mathrm{Pd}$ reaches to $y=0.5$ at $1588 \mathrm{~K}$. Here, $y$ represents the mol fraction of Cr. The melting temperature $T_{\mathrm{m}}$ is $2136 \mathrm{~K}$ and $1828 \mathrm{~K}$ for $\mathrm{Cr}$ and $\mathrm{Pd}$, respectively, and hence $T_{\mathrm{m}}$ is much higher for $\mathrm{Cr}$ than for $\mathrm{Pd}$. Therefore, we may intuitively expect that alloying of Pd with $\mathrm{Cr}$ decelerates the interdiffusion between $\mathrm{Pd}$ and $\mathrm{Sn}$ and thus inhibits the formation of the $\mathrm{Pd}-\mathrm{Sn}$ compounds at solid-state temperatures. Unfortunately, however, no reliable information is available for effects of $\mathrm{Cr}$ on the compound formation. In the present study, the influence of $\mathrm{Cr}$ on the solid-state reactive diffusion between $\mathrm{Pd}$ and $\mathrm{Sn}$ was experimentally examined using $\mathrm{Sn} /(\mathrm{Pd}-\mathrm{Cr}) / \mathrm{Sn}$ diffusion couples with $\mathrm{Cr}$ 
concentrations of $y=0.1-0.3$ in the temperature range of $433-473 \mathrm{~K}$. The rate-controlling process of the reactive diffusion was discussed on the basis of the experimental result.

\section{Experimental}

Plate specimens of pure $\mathrm{Sn}$ with a size of $12 \mathrm{~mm} \times$ $5 \mathrm{~mm} \times 2 \mathrm{~mm}$ were prepared by cold rolling and spark erosion from a commercial $1 \mathrm{~kg}$ rectangular ingot of pure $\mathrm{Sn}$ with a purity of $99.99 \%$. The cold-rolled plate specimens were separately annealed in evacuated silica capsules at $473 \mathrm{~K}$ for $2 \mathrm{~h}$, followed by air cooling without breaking the capsules. The annealed Sn plate specimens were chemically polished in an etchant consisting of $20 \mathrm{vol} \%$ of nitric acid, $20 \mathrm{vol} \%$ of hydrochloric acid and $60 \mathrm{vol} \%$ of distilled water. The two surfaces with an area of $12 \mathrm{~mm} \times 5 \mathrm{~mm}$ of each Sn plate specimen were mechanically polished on \# 800 emery paper. One of the two polished surfaces was again mechanically polished on \# 1500-4000 emery papers until a depth of $100 \mu \mathrm{m}$, and then finished using diamond with a diameter of $1 \mu \mathrm{m}$.

Binary $\mathrm{Pd}-\mathrm{Cr}$ alloys with $\mathrm{Cr}$ mol fractions of $y=0.110$, $0.215,0.323$ and 0.336 were made as $20 \mathrm{~g}$ button ingots by argon arc melting from pure $\mathrm{Pd}$ and $\mathrm{Cr}$ with purities of 99.9 and $99.99 \%$, respectively. Plate specimens with dimensions of $15 \mathrm{~mm} \times 7 \mathrm{~mm} \times 3 \mathrm{~mm}$ were cut from the button ingot, and then separately homogenized in evacuated silica capsules at $1173 \mathrm{~K}$ for $336 \mathrm{~h}$, followed by air cooling without breaking the capsules. Sheet specimens with a size of $12 \mathrm{~mm} \times$ $5 \mathrm{~mm} \times 0.2 \mathrm{~mm}$ were prepared by cold rolling and spark erosion from the homogenized plate specimen. Each sheet specimen was annealed in an evacuated silica capsule at $1173 \mathrm{~K}$ for $2 \mathrm{~h}$, followed by water quenching without breaking the capsule. The annealed sheet specimen was chemically polished in nitrohydrochloric acid for $60 \mathrm{~s}$.

After chemical polishing, a $\mathrm{Pd}-\mathrm{Cr}$ sheet specimen was immediately sandwiched between the finished surfaces of two freshly prepared Sn plate specimens in ethanol by the technique used in a previous study. ${ }^{18)}$ Sandwich $\mathrm{Sn} /(\mathrm{Pd}-\mathrm{Cr}) /$ $\mathrm{Sn}$ couples were entirely dried, and then heat treated for diffusion bonding in an oil bath with silicone oil at temperatures of $433 \mathrm{~K}, 453 \mathrm{~K}$ and $473 \mathrm{~K}$ for $3 \mathrm{~h}, 0.75 \mathrm{~h}$ and $0.5 \mathrm{~h}$, respectively. After the heat treatment, the diffusion couples were isothermally annealed in this temperature range for various times up to $357 \mathrm{~h}$. The summation of the heattreating and annealing times is hereafter merely called the annealing time $t$, and the annealing temperature is denoted by $T$. The chemical composition of the $\mathrm{Pd}-\mathrm{Cr}$ alloy is described as $\mathrm{Pd}-y \mathrm{Cr}$, where $y$ is the mol fraction of $\mathrm{Cr}$ as mentioned earlier. The $\mathrm{Pd}-0.110 \mathrm{Cr}, \mathrm{Pd}-0.215 \mathrm{Cr}, \mathrm{Pd}-0.323 \mathrm{Cr}$ and $\mathrm{Pd}-$ $0.336 \mathrm{Cr}$ alloys are designated alloys $\mathrm{C} 1, \mathrm{C} 2, \mathrm{C} 3$ and $\mathrm{C} 4$, respectively, and the diffusion couples with alloys $\mathrm{C} 1, \mathrm{C} 2, \mathrm{C} 3$ and $\mathrm{C} 4$ are denominated diffusion couples $\mathrm{C} 1, \mathrm{C} 2, \mathrm{C} 3$ and $\mathrm{C} 4$, respectively. As to diffusion couple $\mathrm{C} 4$, isothermal annealing was extended to $t=2100 \mathrm{~h}$ at $T=433-473 \mathrm{~K}$. Cross-sections of the annealed diffusion couple were mechanically polished using diamond with diameters of 15,3 and $1 \mu \mathrm{m}$, and then finished with an OP-S liquid manufactured by Struers Ltd. The microstructure of the cross-

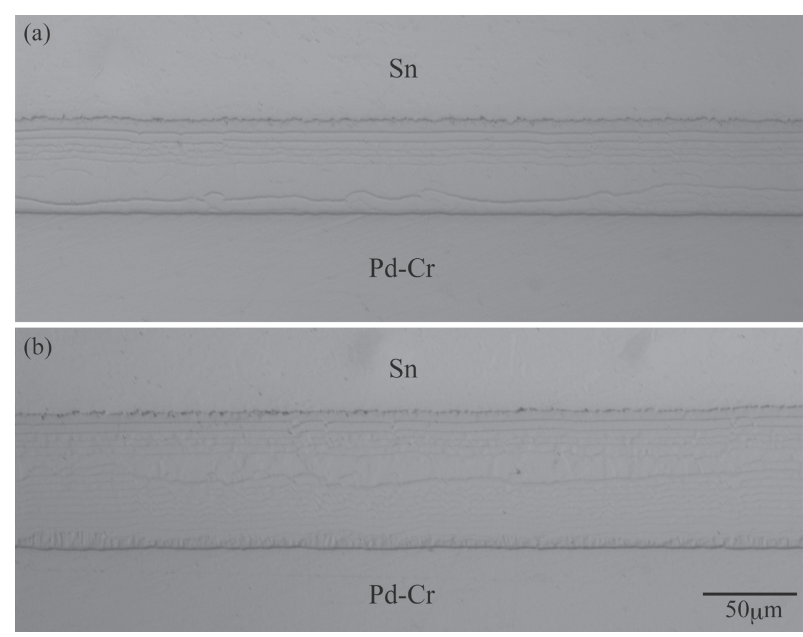

Fig. 1 Cross-sectional DICOM photographs of the compound layer in diffusion couple $\mathrm{C} 2$ annealed at $T=473 \mathrm{~K}$ for (a) $t=9 \mathrm{~h}\left(3.24 \times 10^{4} \mathrm{~s}\right)$ and (b) $t=18 \mathrm{~h}\left(6.48 \times 10^{4} \mathrm{~s}\right)$

section was observed by differential interference contrast optical microscopy (DICOM) and scanning electron microscopy (SEM). A backscattered electron image (BEI) technique was preferably used in the SEM observation. Concentrations of $\mathrm{Sn}, \mathrm{Pd}$ and $\mathrm{Cr}$ in each phase on the crosssection were measured by electron probe microanalysis (EPMA). Diffusion couples C1-C3 were used mainly for the kinetic observation, and diffusion couple $\mathrm{C} 4$ was utilized only for the EPMA measurement.

\section{Results and Discussion}

\subsection{Microstructure}

Typical cross-sectional DICOM photographs of diffusion couple $\mathrm{C} 2$ annealed at $T=473 \mathrm{~K}$ are shown in Fig. 1. Figure 1(a) and 1(b) indicates the DICOM photographs of $t=9 \mathrm{~h}\left(3.24 \times 10^{4} \mathrm{~s}\right)$ and $t=18 \mathrm{~h}\left(6.48 \times 10^{4} \mathrm{~s}\right)$, respectively. In these photographs, the top region is the $\mathrm{Sn}$ specimen, and the bottom region is the $\mathrm{Pd}-\mathrm{Cr}$ alloy. Here, alloys $\mathrm{C} 1-\mathrm{C} 4$ possess the single-phase microstructure with the face-centered cubic (fcc) crystal structure. As can be seen in Fig. 1, a compound layer composed of matrices with different grain sizes and lamellar phases is produced between the $\mathrm{Sn}$ and the $\mathrm{Pd}-\mathrm{Cr}$ alloy. If we observe the edge of diffusion couple on the cross-section, we can find the location of the original $(\mathrm{Pd}-\mathrm{Cr}) / \mathrm{Sn}$ interface. This observation indicates that the compound layer grows mainly into the Sn but slightly towards the $\mathrm{Pd}-\mathrm{Cr}$ alloy. To identify each phase, concentration profiles of $\mathrm{Sn}, \mathrm{Pd}$ and $\mathrm{Cr}$ across the compound layer were determined by EPMA along the direction normal to the original $(\mathrm{Pd}-\mathrm{Cr}) / \mathrm{Sn}$ interface. A result of the diffusion couple in Fig. 1(b) is indicated in Fig. 2. In this figure, the ordinate and the abscissa show the mol fraction $y_{i}$ of component $i$ and the distance $x$ measured from an arbitrary origin, respectively, and open circles, rhombuses and squares represent the mol fractions $y_{\mathrm{Sn}}, y_{\mathrm{Pd}}$ and $y_{\mathrm{Cr}}$, respectively. As can be seen, the matrices are $\mathrm{PdSn}_{2}, \mathrm{PdSn}_{3}$ and $\mathrm{PdSn}_{4}$ from the $\mathrm{Pd}-\mathrm{Cr}$ side to the $\mathrm{Sn}$ side, and the thickness is much smaller for $\mathrm{PdSn}_{2}$ and $\mathrm{PdSn}_{3}$ than for $\mathrm{PdSn}_{4}$. Comparing Fig. 1(b) with Fig. 2, the fine-grained contrast may be 


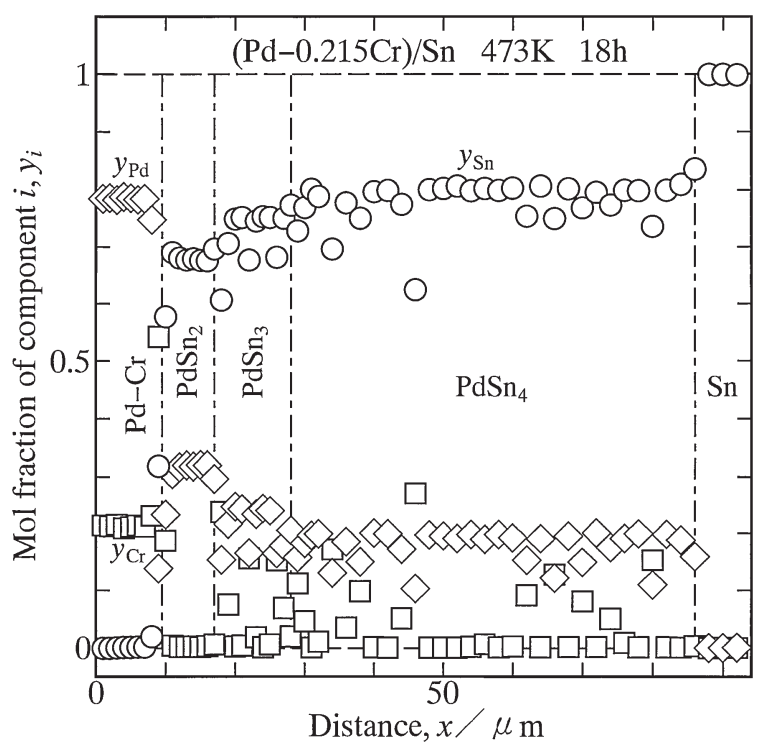

Fig. 2 Concentration profiles of $\mathrm{Sn}, \mathrm{Pd}$ and $\mathrm{Cr}$ across the compound layer in diffusion couple $\mathrm{C} 2$ shown in Fig. 1(b).

recognized for $\mathrm{PdSn}_{2}$ but not for $\mathrm{PdSn}_{3}$ and $\mathrm{PdSn}_{4}$. Thus, in Fig. 1(b), the interface is distinguishable between $\mathrm{PdSn}_{2}$ and $\mathrm{PdSn}_{3}$ but not between $\mathrm{PdSn}_{3}$ and $\mathrm{PdSn}_{4}$. Since the thickness of the compound layer is smaller for Fig. 1(a) than for Fig. 1(b), however, $\mathrm{PdSn}_{2}$ is invisible in Fig. 1(a). Although the concentration of $\mathrm{Cr}$ is much larger for the lamellar phases than for the matrices, the thicknesses of the lamellar phases in diffusion couples $\mathrm{C} 1-\mathrm{C} 3$ were not sufficiently large com- pared with the spatial resolution of EPMA. Consequently, unlike the matrices, the chemical compositions of the lamellar phases could not be reliably determined by EPMA.

Cross-sectional BEI photographs of diffusion couple $\mathrm{C} 4$ with $T=473 \mathrm{~K}$ and $t=2100 \mathrm{~h}\left(7.56 \times 10^{6} \mathrm{~s}\right)$ are shown in Fig. 3. In Fig. 3(a), the top and bottom regions are the Sn and the $\mathrm{Pd}-\mathrm{Cr}$ alloy, respectively. As can be seen, the compound layer with a thickness of about $500 \mu \mathrm{m}$ is produced between the $\mathrm{Sn}$ and the $\mathrm{Pd}-\mathrm{Cr}$ alloy. The lower, middle and upper parts of the compound layer are magnified in Fig. 3(b), 3(c) and 3(d), respectively. At each part, concentration profiles of $\mathrm{Sn}, \mathrm{Pd}$ and $\mathrm{Cr}$ across each second phase were determined by EPMA along the direction normal to the original $(\mathrm{Pd}-\mathrm{Cr}) / \mathrm{Sn}$ interface. Results are shown in Fig. 4. As indicated in Fig. 3(a), a dark layer with a rather uniform thickness is formed between the $\mathrm{Pd}-\mathrm{Cr}$ alloy and $\mathrm{PdSn}_{2}$. The concentration profiles across this dark layer are shown in Fig. 4(a). According to Fig. 4(a), the dark layer is $\left(\mathrm{Cr}_{0.9} \mathrm{Pd}_{0.1}\right)_{3} \mathrm{Sn}$. On the other hand, the result in Fig. 4(b) corresponds to the region in Fig. 3(b), and those in Fig. 4(c) and 4(d) correlate to the medium and upper regions in Fig. 3(c), respectively. Figures 3(b) and 4(b) show that $\left(\mathrm{Cr}_{0.9} \mathrm{Pd}_{0.1}\right)_{3} \mathrm{Sn}$ is also distributed as coarse flakes in $\mathrm{PdSn}_{3}$. Since the fine-grained contrast is rather discerned for $\mathrm{PdSn}_{2}$ but not for $\mathrm{PdSn}_{3}$ and $\mathrm{PdSn}_{4}$ in Fig. 3(b), the $\mathrm{PdSn}_{2} / \mathrm{PdSn}_{3}$ interface is slightly distinguishable in this figure. In contrast, thin flakes composed of darker and brighter phases are recognized in Fig. 3(c). Furthermore, the darker phase is surrounded by the brighter phase. Figure 4(c) indicates that the darker and brighter phases are $\left(\mathrm{Cr}_{0.95} \mathrm{Pd}_{0.05}\right)_{2} \mathrm{Sn}$ and $\left(\mathrm{Cr}_{0.9} \mathrm{Pd}_{0.1}\right) \mathrm{Sn}$,
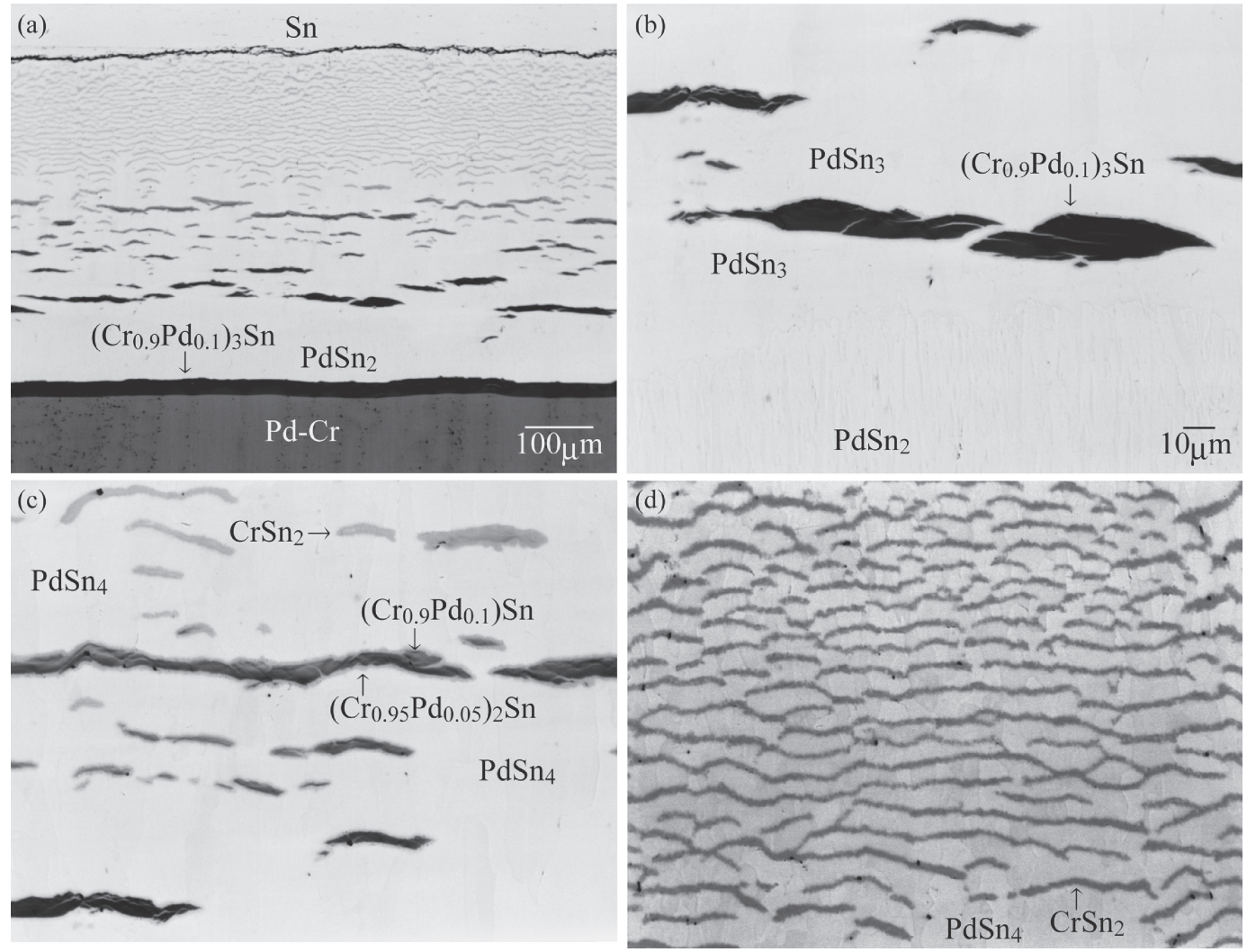

Fig. 3 Cross-sectional BEI photographs of the compound layer in diffusion couple $\mathrm{C} 4$ with $T=473 \mathrm{~K}$ and $t=2100 \mathrm{~h}\left(7.56 \times 10^{6} \mathrm{~s}\right)$ :

(a) whole region, (b) lower part, (c) middle part and (d) upper part. 

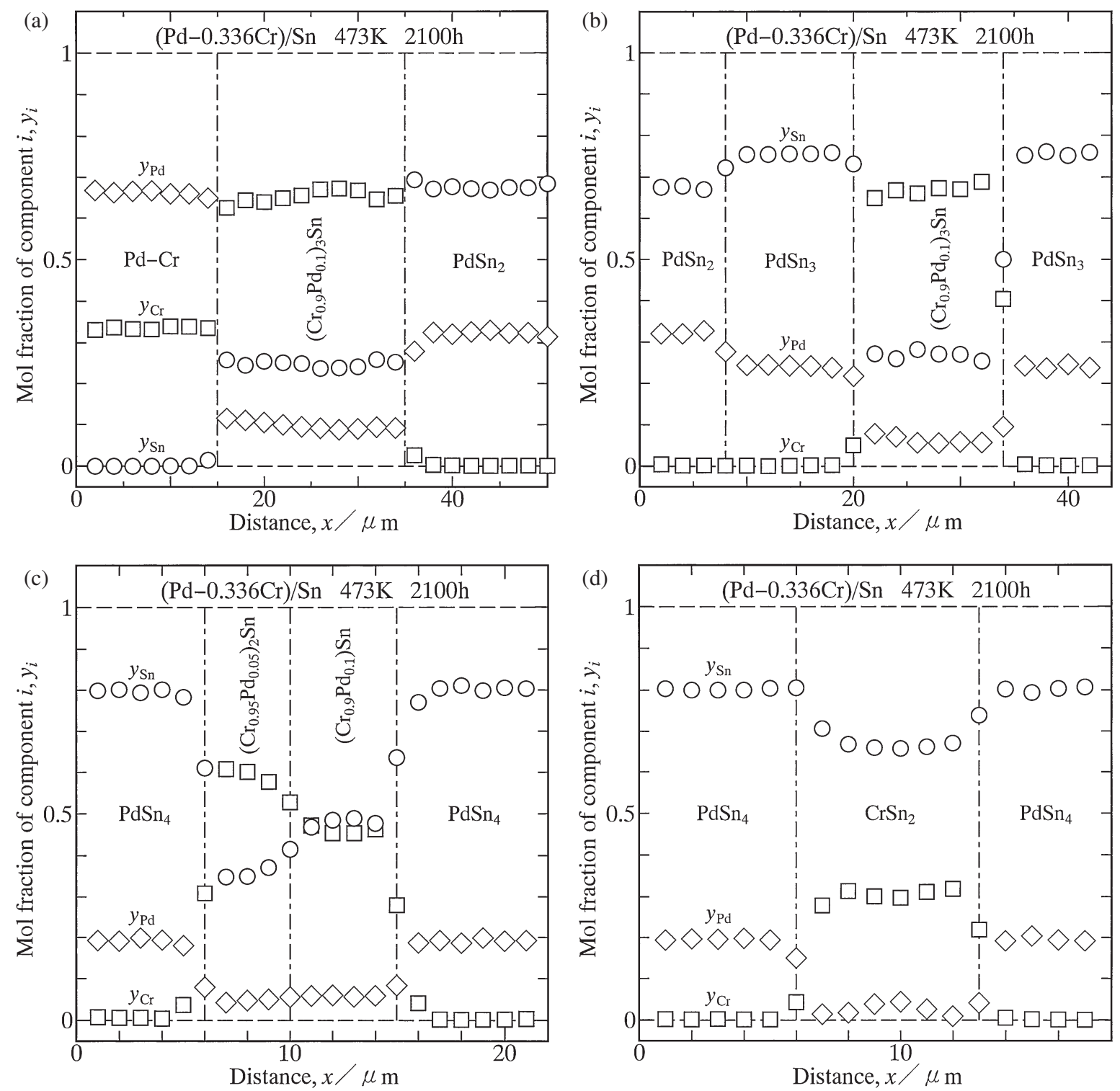

Fig. 4 Concentration profiles of $\mathrm{Sn}, \mathrm{Pd}$ and $\mathrm{Cr}$ across various phases of the compound layer for diffusion couple $\mathrm{C} 4$ shown in Fig. 3 : (a) the dark layer between the Pd-Cr alloy and the compound layer in Fig. 3(a), (b) a coarse flake in Fig. 3(b), (c) a thin flake composed of darker and brighter phases, and (d) the lamellar microstructure in Fig. 3(d).

respectively, and the matrix is $\mathrm{PdSn}_{4}$. For the medium region in Fig. 3(c), however, the thickness of $\left(\mathrm{Cr}_{0.9} \mathrm{Pd}_{0.1}\right) \mathrm{Sn}$ is not large enough to conduct the EPMA measurement reliably. Thus, the result in Fig. 4(c) actually corresponds to a different region of the diffusion couple in Fig. 3. On the other hand, a rather fine lamellar microstructure is observed in Fig. 3(d). Figure 4(d) represents that the matrix and the second phase in the fine lamellar microstructure are $\mathrm{PdSn}_{4}$ and $\mathrm{CrSn}_{2}$, respectively.

The experimental points in Fig. 4 are plotted as a diffusion path with open circles in a composition triangle of the ternary $\mathrm{Sn}-\mathrm{Pd}-\mathrm{Cr}$ system in Fig. 5. According to Fig. 4(a) and 4(b), $\left(\mathrm{Cr}_{0.9} \mathrm{Pd}_{0.1}\right)_{3} \mathrm{Sn}$ is directly contacted with both $\mathrm{PdSn}_{2}$ and $\mathrm{PdSn}_{3}$. This implies that the three-phase equilibrium of $\mathrm{PdSn}_{2}+\mathrm{PdSn}_{3}+\left(\mathrm{Cr}_{0.9} \mathrm{Pd}_{0.1}\right)_{3} \mathrm{Sn}$ exists in this ternary system. On the other hand, as indicated in Fig. 4(c) and 4(d), $\left(\mathrm{Cr}_{0.95} \mathrm{Pd}_{0.05}\right)_{2} \mathrm{Sn},\left(\mathrm{Cr}_{0.9} \mathrm{Pd}_{0.1}\right) \mathrm{Sn}$ and $\mathrm{CrSn}_{2}$ are distributed in $\mathrm{PdSn}_{4}$. This means that there appear the three-phase equilibrium of $\mathrm{PdSn}_{4}+\left(\mathrm{Cr}_{0.95} \mathrm{Pd}_{0.05}\right)_{2} \mathrm{Sn}+\left(\mathrm{Cr}_{0.9} \mathrm{Pd}_{0.1}\right) \mathrm{Sn}$ and that of $\mathrm{PdSn}_{4}+\left(\mathrm{Cr}_{0.9} \mathrm{Pd}_{0.1}\right) \mathrm{Sn}+\mathrm{CrSn}_{2}$. As reported in previous studies, at $T=433-473 \mathrm{~K}$, the three-phase equilibrium of $\mathrm{Sn}+\mathrm{PdSn}_{4}+\mathrm{CrSn}_{2}$ exists in the ternary $\mathrm{Sn}-\mathrm{Pd}-$ $\mathrm{Cr}$ system, ${ }^{21)}$ and the two-phase equilibrium of $\mathrm{Sn}+\mathrm{CrSn}_{2}$ appears in the binary $\mathrm{Sn}-\mathrm{Cr}$ system. ${ }^{22)}$ The experimental compositions of these two-phase and three-phase equilibria are shown as open triangles and squares, respectively, in Fig. 5. Although the solubility of $\mathrm{Pd}$ in $\mathrm{CrSn}_{2}$ is small, the solubility range of $\mathrm{CrSn}_{2}$ is slightly extended to the $\mathrm{Sn}$-rich side by addition of $\mathrm{Pd}$ into $\mathrm{CrSn}_{2}$. The same phase relationships as Fig. 5 were observed also at $T=433 \mathrm{~K}$ and $453 \mathrm{~K}$. Since the volume fraction of each $\mathrm{Cr}$-rich compound on the cross-section is very small even for diffusion couple C4 with $t=2100 \mathrm{~h}\left(7.56 \times 10^{6} \mathrm{~s}\right)$, however, the crystal structures of the Cr-rich compounds could not be determined by an X-ray diffraction technique.

As shown in Fig. 3, the compound layer with periodic lamellar microstructure is formed owing to the reactive diffusion in the $(\mathrm{Pd}-\mathrm{Cr}) / \mathrm{Sn}$ system at $T=433-473 \mathrm{~K}$. This 


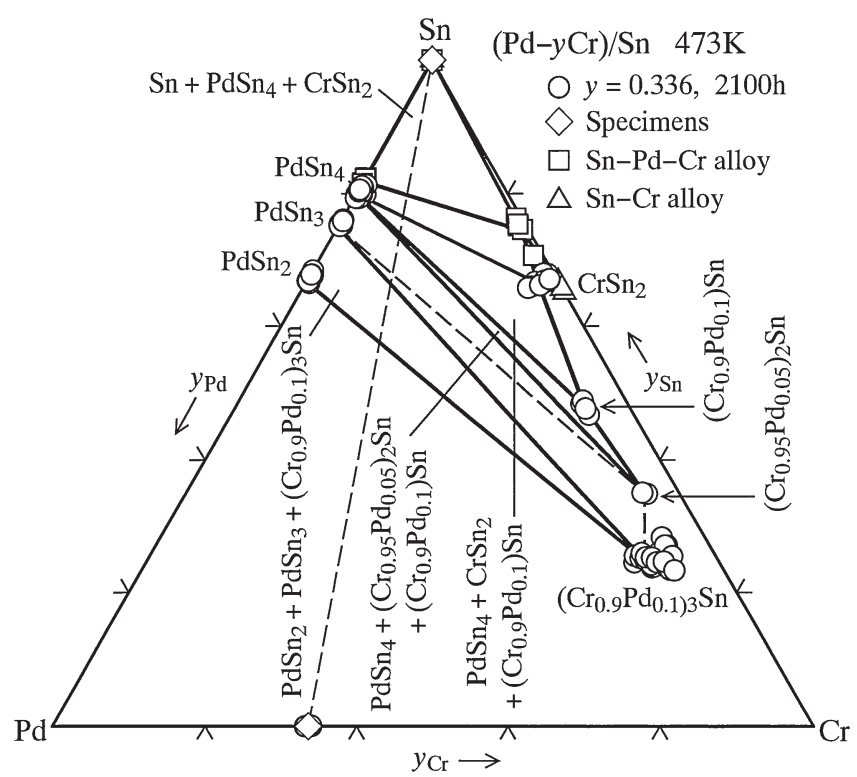

Fig. 5 Diffusion path for the concentration profiles shown in Fig. 4. The experimental compositions for the three-phase equilibrium of $\mathrm{Sn}+$ $\mathrm{PdSn}_{4}+\mathrm{CrSn}_{2}$ in the ternary $\mathrm{Sn}-\mathrm{Pd}-\mathrm{Cr}$ system ${ }^{21)}$ and the two-phase equilibrium of $\mathrm{Sn}+\mathrm{CrSn}_{2}$ in the binary $\mathrm{Sn}-\mathrm{Cr}$ system $^{22}$ ) are also indicated as open squares and triangles, respectively.

type of compound formation is usually called a Liesegang phenomenon. Originally, Liesegang found periodic precipitation of a compound in a solvent. ${ }^{23)}$ On the other hand, a solid-state Liesegang phenomenon was observed by Osinski et al. for the reactive diffusion in the $(\mathrm{Fe}-\mathrm{Si}) / \mathrm{Zn}$ system at $T=668 \mathrm{~K}^{24)}$ In a previous study, ${ }^{22)}$ a solid-state Liesegang phenomenon was recognized also for the reactive diffusion in the $(\mathrm{Ni}-\mathrm{Cr}) / \mathrm{Sn}$ system at $T=453-473 \mathrm{~K}$. The compound formation due to a solid-state Liesegang phenomenon can be explained by a geometrical model reported in a previous study. $^{22)}$

As mentioned in Section 1, the solid-state reactive diffusion in the $\mathrm{Pd} / \mathrm{Sn}$ system was experimentally observed using the $\mathrm{Sn} / \mathrm{Pd} / \mathrm{Sn}$ diffusion couple in a previous study. ${ }^{16}$ ) Hereafter, the $\mathrm{Sn} / \mathrm{Pd} / \mathrm{Sn}$ diffusion couple is called diffusion couple C0. In diffusion couple C0, ${ }^{16)} \mathrm{PdSn}_{4}, \mathrm{PdSn}_{3}$ and $\mathrm{PdSn}_{2}$ were observed at $T=433 \mathrm{~K}$, but only $\mathrm{PdSn}_{4}$ and $\mathrm{PdSn}_{3}$ were discerned at $T=453-473 \mathrm{~K}$. On the other hand, in diffusion couples $\mathrm{C} 1-\mathrm{C} 4, \mathrm{PdSn}_{2}$ as well as $\mathrm{PdSn}_{4}$ and $\mathrm{PdSn}_{3}$ was clearly recognized at $T=433-473 \mathrm{~K}$. Hence, the phase stability and the relative growth rate among $\mathrm{PdSn}_{4}, \mathrm{PdSn}_{3}$ and $\mathrm{PdSn}_{2}$ vary depending on the chemical composition of the $\mathrm{Pd}-$ $\mathrm{Cr}$ alloy in the $\mathrm{Sn} /(\mathrm{Pd}-\mathrm{Cr}) / \mathrm{Sn}$ diffusion couple, though the solubilities of $\mathrm{Cr}$ in $\mathrm{PdSn}_{4}, \mathrm{PdSn}_{3}$ and $\mathrm{PdSn}_{2}$ are negligible as mentioned earlier. In the binary $\mathrm{Pd}-\mathrm{Sn}$ system, ${ }^{20)}$ ten $\mathrm{Pd}-\mathrm{Sn}$ compounds with different stoichiometries appear as stable phases at $T=433-473 \mathrm{~K}$. Of the ten compounds, however, only $\mathrm{PdSn}_{4}, \mathrm{PdSn}_{3}$ and $\mathrm{PdSn}_{2}$ were clearly recognized in diffusion couples $\mathrm{C} 1-\mathrm{C} 4$. Therefore, the phase equilibria among the other seven $\mathrm{Pd}-\mathrm{Sn}$ compounds and the Cr-rich compounds were not determined in the present study.

\subsection{Growth behavior of intermetallic layer}

As previously mentioned, various compounds are produced in diffusion couples $\mathrm{C} 1-\mathrm{C} 4$. The chemical composi-

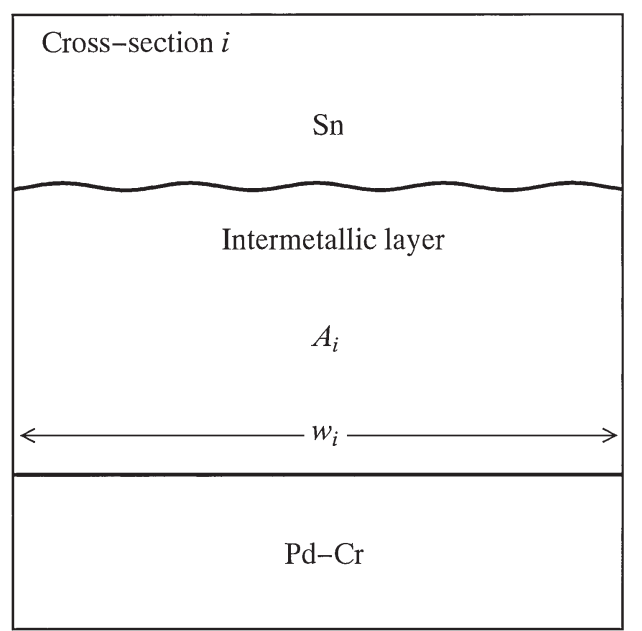

Fig. 6 Schematic of the morphology of the intermetallic layer for crosssection $i$.

tion of each compound was reliably determined by EPMA for diffusion couple $\mathrm{C} 4$ but not for diffusion couples $\mathrm{C} 1-\mathrm{C} 3$. Although the $\mathrm{PdSn}_{2} / \mathrm{PdSn}_{3}$ interface is distinguishable in DICOM photographs, $\mathrm{PdSn}_{2}$ is invisible due to small thicknesses at short annealing times. Hence, for the kinetic observation using diffusion couples $\mathrm{C} 1-\mathrm{C} 3$, only the overall layer growth was examined experimentally. However, the thickness is much greater for $\mathrm{PdSn}_{4}$ than for $\mathrm{PdSn}_{2}$ and $\mathrm{PdSn}_{3}$, and the volume fraction is much smaller for the second phases than for $\mathrm{PdSn}_{4}$. As a consequence, the layer growth of $\mathrm{PdSn}_{4}$ predominantly governs the overall layer growth. Hereafter, the layer consisting of various compounds is merely called the intermetallic layer. The schematic morphology of the intermetallic layer on cross-section $i$ is shown in Fig. 6. From DICOM photographs such as that shown in Fig. 1, the area $A_{\mathrm{i}}$ of the intermetallic layer corresponding to the partial length $w_{\mathrm{i}}$ of the original $(\mathrm{Pd}-\mathrm{Cr}) /$ $\mathrm{Sn}$ interface in Fig. 6 was measured on each cross-section, and then the sums $A$ and $w$ were obtained as ${ }^{18)}$

$$
A=\sum_{i=1}^{m} A_{\mathrm{i}}
$$

and

$$
w=\sum_{i=1}^{m} w_{\mathrm{i}}
$$

from $A_{\mathrm{i}}$ and $w_{\mathrm{i}}$, respectively, where $m \geq 5$. Using the values of $A$ and $w$, the total thickness $l$ of the intermetallic layer was evaluated at each annealing time $t$ by the equation ${ }^{18)}$

$$
l=\frac{A}{w} .
$$

Here, $w$ and $A$ are the total length parallel to the original (Pd$\mathrm{Cr}$ )/Sn interface and the total area of the intermetallic layer, respectively, on the cross-section. The results of diffusion couples $\mathrm{C} 0,{ }^{16)} \mathrm{C} 1, \mathrm{C} 2$ and $\mathrm{C} 3$ at $T=433-473 \mathrm{~K}$ are plotted as open circles, triangles, rhombuses and squares, respectively, in Fig. 7(a)-(c). According to Fig. 3(a), a very thin crack is observed along the $\mathrm{PdSn}_{4} / \mathrm{Sn}$ interface in diffusion couple $\mathrm{C} 4$. This thin crack may be formed by aggregation of Kirkendall voids during extended annealing. On the other 

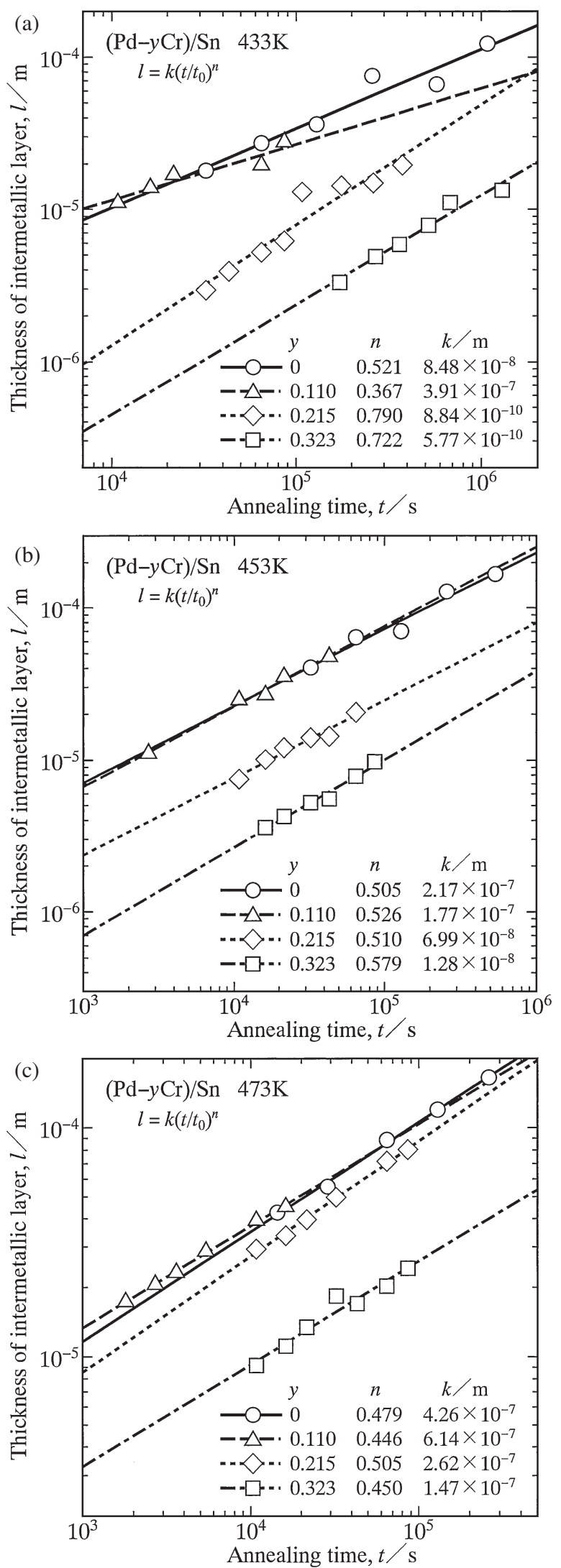

Fig. 7 The total thickness $l$ of the intermetallic layer versus the annealing time $t$ for diffusion couples $\mathrm{C} 0,{ }^{16)} \mathrm{C} 1, \mathrm{C} 2$ and $\mathrm{C} 3$ shown as open circles, triangles, rhombuses and squares, respectively, at (a) $T=433 \mathrm{~K}$, (b) $T=$ $453 \mathrm{~K}$ and (c) $T=473 \mathrm{~K}$.

hand, as indicated in Fig. 1, such a crack was not recognized for diffusion couples $\mathrm{C} 0-\mathrm{C} 3$ within the experimental annealing times. Since the values of $l$ measured for diffusion

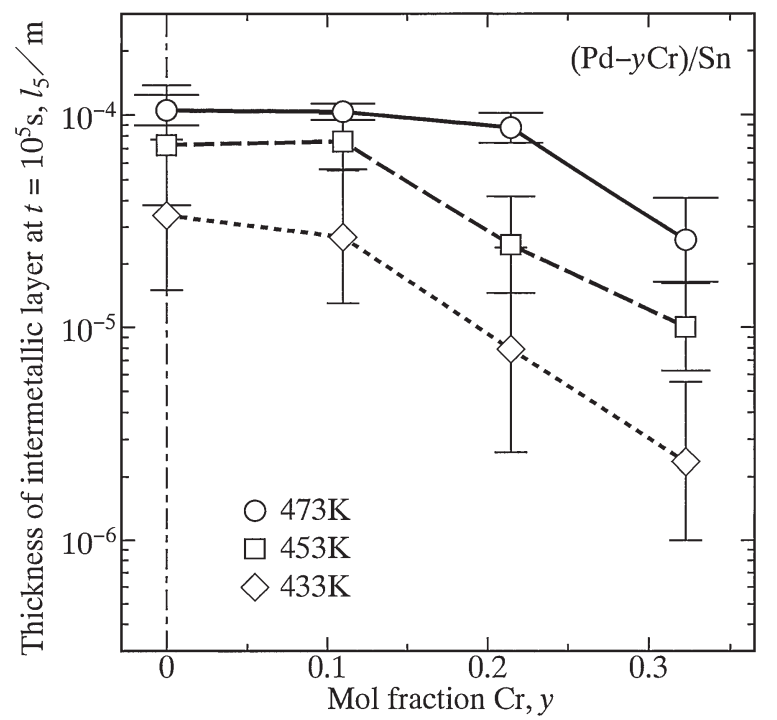

Fig. 8 The thickness $l_{5}$ at $t=10^{5} \mathrm{~s}$ versus the mol fraction $y$ of $\mathrm{Cr}$ in the $\mathrm{Pd}-\mathrm{Cr}$ alloy at $T=433 \mathrm{~K}, 453 \mathrm{~K}$ and $473 \mathrm{~K}$ shown as open rhombuses, squares and circles, respectively, with error bars. The corresponding results of $y=0^{16)}$ are also represented.

couple $\mathrm{C} 4$ are considerably scattered due to the crack formation, only the results of diffusion couples $\mathrm{C} 0-\mathrm{C} 3$ are included in Fig. 7. In this figure, the ordinate and the abscissa show the logarithms of $l$ and $t$, respectively. As can be seen, the thickness $l$ monotonically increases with increasing annealing time $t$. Furthermore, the plotted points of each diffusion couple are located well on a straight line. Consequently, $l$ is expressed as a power function of $t$ as follows.

$$
l=k\left(\frac{t}{t_{0}}\right)^{n}
$$

Here, $t_{0}$ is unit time, $1 \mathrm{~s}$. It is adopted to make the argument $t / t_{0}$ of the power function dimensionless. The proportionality coefficient $k$ has the same dimension as the thickness $l$, and the exponent $n$ is dimensionless. From the points plotted in Fig. 7, $k$ and $n$ were determined by the least-squares method as indicated with various straight lines. The determined values are shown in Fig. 7. Since $n$ varies depending on $y$, it is rather difficult to find a systematic relationship between $k$ and $y$. Therefore, to estimate the composition dependence of the overall growth rate of the intermetallic layer, the thickness $l_{5}$ at $t=10^{5} \mathrm{~s}$ is plotted against $y$ as open rhombuses, squares and circles for $T=433 \mathrm{~K}, 453 \mathrm{~K}$ and $473 \mathrm{~K}$, respectively, in Fig. 8. At $T=433-453 \mathrm{~K}, l_{5}$ is rather insensitive to $y$ at $y<0.1$ but monotonically decreases with increasing value of $y$ at $y>0.1$. On the other hand, at $T=473 \mathrm{~K}, l_{5}$ remains almost constant independent of $y$ at $y<0.2$ but gradually decreases with increasing value of $y$ at $y>0.2$. As previously mentioned, the intermetallic layer consists of the Pd-Sn compounds dispersed with the lamellar Cr-rich compounds. In order for the intermetallic layer to grow during annealing, the interdiffusion among the constituent components should occur across the Cr-rich compounds as well as the Pd-Sn compounds. The volume fraction $f$ of the Cr-rich compounds in the intermetallic layer increases with increasing value of $y$. Hence, the increase in $f$ causes the decrease in $l_{5}$. This implies 
that the interdiffusion is more sluggish for the Cr-rich compounds than for the $\mathrm{Pd}-\mathrm{Sn}$ compounds. Furthermore, the dependencies of $l_{5}$ on $y$ and $T$ in Fig. 8 indicate that the difference of the interdiffusion between the $\mathrm{Cr}$-rich compounds and the Pd-Sn compounds increases with decreasing annealing temperature. Consequently, it is concluded that the Cr-rich compounds work as effective diffusion barriers against the growth of the intermetallic layer at $y>0.2$.

\subsection{Rate-controlling process of intermetallic growth}

The values of $n$ at $T=433 \mathrm{~K}, 453 \mathrm{~K}$ and $473 \mathrm{~K}$ are plotted against $y$ as open circles with error bars in Fig. 9(a), 9(b) and 9(c), respectively. The result in Fig. 9 is represented in a different manner in Fig. 10. In this figure, the ordinate and the abscissa show $n$ and $T$, respectively, and open circles, triangles, rhombuses and squares indicate the results of $y=0,{ }^{16)} 0.110,0.215$ and 0.323 , respectively. If the layer growth of the intermetallic layer is controlled by volume diffusion, $n$ is equal to $0.5 .^{25-32)}$ On the other hand, boundary diffusion may govern the layer growth at low temperatures where volume diffusion is frozen out. When the layer growth is controlled by boundary diffusion across the intermetallic layer and grain growth occurs in the intermetallic layer, $n$ becomes smaller than $0.5 .{ }^{17)}$ However, $n$ is equal to 0.5 even for the layer growth controlled by boundary diffusion unless grain growth takes place. ${ }^{17)}$ Consequently, in the case of $n=0.5$, there are two possibilities for the rate-controlling process. In such a case, the rate-controlling process cannot be conclusively determined only from the value of $n$. To estimate the rate-controlling process for the layer growth, the grain growth in the intermetallic layer was experimentally examined for $y=0$ in a previous study. ${ }^{16)}$ This experiment indicates that the grain growth actually occurs at $T=433$ $473 \mathrm{~K}$. On the other hand, grain growth in the $(\mathrm{Pd}-\mathrm{Ni}) / \mathrm{Sn}$ system was experimentally observed in a previous study. ${ }^{33)}$ Also in the $(\mathrm{Pd}-\mathrm{Ni}) / \mathrm{Sn}$ system, like the $(\mathrm{Pd}-\mathrm{Cr}) / \mathrm{Sn}$ system, $\mathrm{PdSn}_{4}, \mathrm{PdSn}_{3}$ and $\mathrm{PdSn}_{2}$ are formed at $T=433-473 \mathrm{~K}$ due to reactive diffusion. In the $\mathrm{Pd}-\mathrm{Sn}$ compounds, however, the solubility is much greater for $\mathrm{Ni}$ than for $\mathrm{Cr}^{33)}$ The grain growth of the intermetallic layer may be decelerated by addition of a solute. Nevertheless, the dissolution of $\mathrm{Ni}$ in the Pd-Sn compounds hardly affects the kinetics of grain growth. ${ }^{33)}$ As a result, we may consider that grain growth takes place also in the $(\mathrm{Pd}-\mathrm{Cr}) / \mathrm{Sn}$ system. Thus, the value $n=0.5$ guarantees that the layer growth is controlled by volume diffusion. According to Fig. 9, $n$ is close to 0.5 independent of $y$ at $T=453-473 \mathrm{~K}$ and for $y=0-0.110$ at $T=433 \mathrm{~K}$. Consequently, it is concluded that the layer growth is mostly controlled by volume diffusion under these experimental conditions.

On the other hand, $n$ takes values of $0.790-0.722$ for $y=0.215-0.323$, respectively, at $T=433 \mathrm{~K}$. If the interface reaction at the moving interface governs the layer growth, $n$ is equivalent to unity. ${ }^{34-41)}$ As mentioned in Section 3.1, the intermetallic layer grows mainly into the $\mathrm{Sn}$. Thus, the values $n=0.790-0.722$ indicate that the layer growth is controlled by the interface reaction at the $\mathrm{PdSn}_{4} / \mathrm{Sn}$ interface as well as the volume diffusion across the intermetallic layer. Such a mixed rate-controlling process of reactive diffusion has been observed for various alloy systems. For instance, the reactive
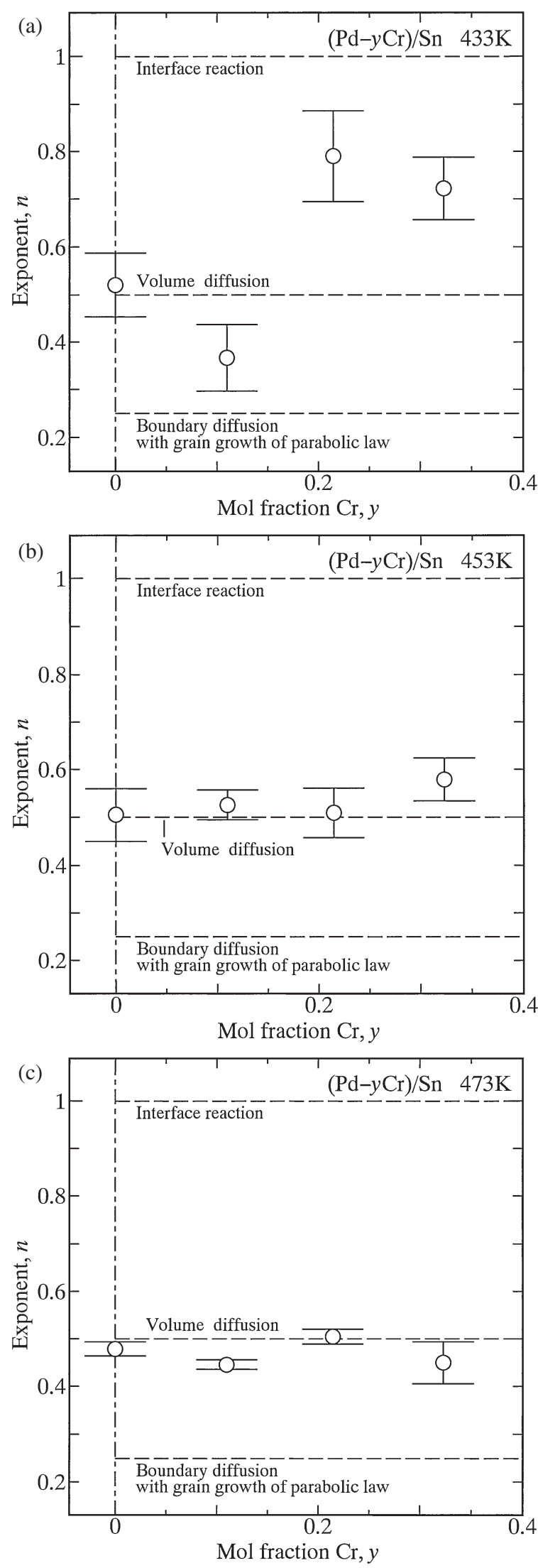

Fig. 9 The exponent $n$ versus the mol fraction $y$ of $\mathrm{Cr}$ in the $\mathrm{Pd}-\mathrm{Cr}$ alloy shown as open circles with error bars at (a) $T=433 \mathrm{~K}$, (b) $T=453 \mathrm{~K}$, and (c) $T=473 \mathrm{~K}$. The corresponding results of $y=0^{16)}$ are also represented.

diffusion in the $(\mathrm{Cu}-\mathrm{Sn}) / \mathrm{Nb}$ system was experimentally examined using diffusion couples consisting of $\mathrm{Cu}-\mathrm{Sn}$ alloys and $\mathrm{Nb}$ in previous studies. ${ }^{34-36)}$ In these experiments, the 


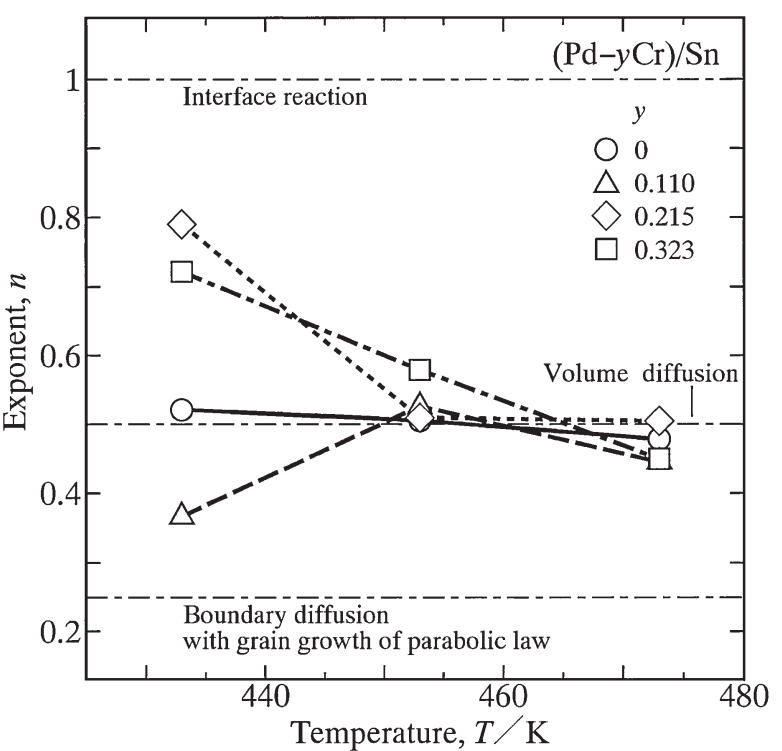

Fig. 10 The exponent $n$ versus the annealing temperature $T$ for $y=0,{ }^{16}$ ) $0.110,0.215$ and 0.323 shown as open circles, triangles, rhombuses and squares, respectively.

diffusion couple was isothermally annealed at $T=923-$ $1053 \mathrm{~K}$. During annealing, a single-phase $\mathrm{Nb}_{3} \mathrm{Sn}$ layer is formed at the original $(\mathrm{Cu}-\mathrm{Sn}) / \mathrm{Nb}$ interface in the diffusion couple, and grows mainly towards the $\mathrm{Nb}$. Here, $\mathrm{Nb}_{3} \mathrm{Sn}$ is one of the most important superconducting materials. Like the $(\mathrm{Pd}-\mathrm{Cr}) / \mathrm{Sn}$ and $(\mathrm{Pd}-\mathrm{Ni}) / \mathrm{Sn}$ systems, eq. (3) holds between the thickness $l$ of the $\mathrm{Nb}_{3} \mathrm{Sn}$ layer and the annealing time $t$. The exponent $n$ in eq. (3) is plotted against the annealing temperature $T$ in Fig. 11. In this figure, open triangles, squares and circles show the results of the $\mathrm{Cu}-$ 8.3Sn, ${ }^{34)} \mathrm{Cu}-8.1 \mathrm{Sn}-0.3 \mathrm{Ti}^{35)}$ and $\mathrm{Cu}-9.3 \mathrm{Sn}-0.3 \mathrm{Ti}^{36)}$ diffusion couples, respectively, where the concentrations of $\mathrm{Sn}$ and Ti are measured in atomic percent. Since the superconducting properties of $\mathrm{Nb}_{3} \mathrm{Sn}$ are improved by addition of $\mathrm{Ti}$ into the $\mathrm{Cu}-\mathrm{Sn}$ alloy, the $\mathrm{Cu}-\mathrm{Sn}$ alloy contains 0.3 at\% of $\mathrm{Ti}$ for the latter two diffusion couples. As can be seen in Fig. 11, $n$ is rather close to unity at $T=923 \mathrm{~K}$. As $T$ increases, however, $n$ gradually decreases, and then reaches to intermediate values of $0.7-0.8$ at $T=1053 \mathrm{~K}$. This means that the interface reaction at the $\mathrm{Nb}_{3} \mathrm{Sn} / \mathrm{Nb}$ interface predominantly controls the growth of the $\mathrm{Nb}_{3} \mathrm{Sn}$ layer at the lower annealing temperatures and the volume diffusion across the $\mathrm{Nb}_{3} \mathrm{Sn}$ layer contributes to the rate-controlling process at the higher annealing temperatures. Hence, the contribution of volume diffusion increases with increasing annealing temperature. As shown in Fig. 10, such temperature dependence of the ratecontrolling process is realized also for $y=0.215-0.323$ in the $(\mathrm{Pd}-\mathrm{Cr}) / \mathrm{Sn}$ system.

For the volume-diffusion rate-controlling process, $n$ is equal to 0.5 as mentioned earlier. In this case, eq. (3) may be rewritten by the following formula.

$$
l^{2}=K t=\frac{k^{2}}{t_{0}} t
$$

Equation (4) is another expression of the parabolic relationship. Here, the parabolic coefficient $K$ has a dimension of area per unit time. As previously mentioned, $n$ is close to 0.5 except $y=0.215-0.323$ at $T=433 \mathrm{~K}$. Thus, excluding this

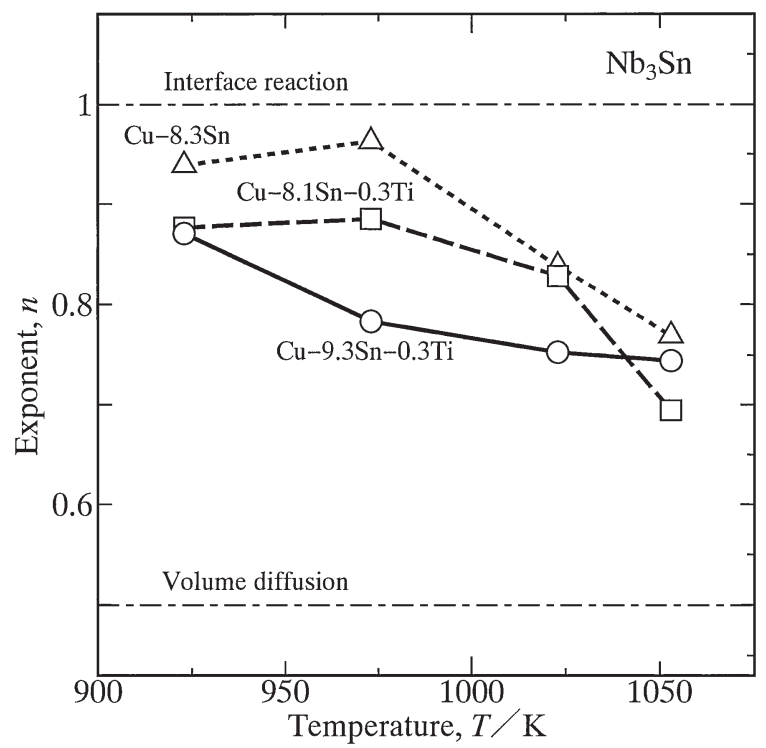

Fig. 11 The exponent $n$ versus the annealing temperature $T$ for the reactive diffusion in the $(\mathrm{Cu}-\mathrm{Sn}) / \mathrm{Nb}$ system. The results of the $\mathrm{Cu}-8.3 \mathrm{Sn},{ }^{34)} \mathrm{Cu}-$ $8.1 \mathrm{Sn}-0.3 \mathrm{Ti}^{35)}$ and $\mathrm{Cu}-9.3 \mathrm{Sn}-0.3 \mathrm{Ti}^{36)}$ diffusion couples are shown as open triangles, squares and circles, respectively.

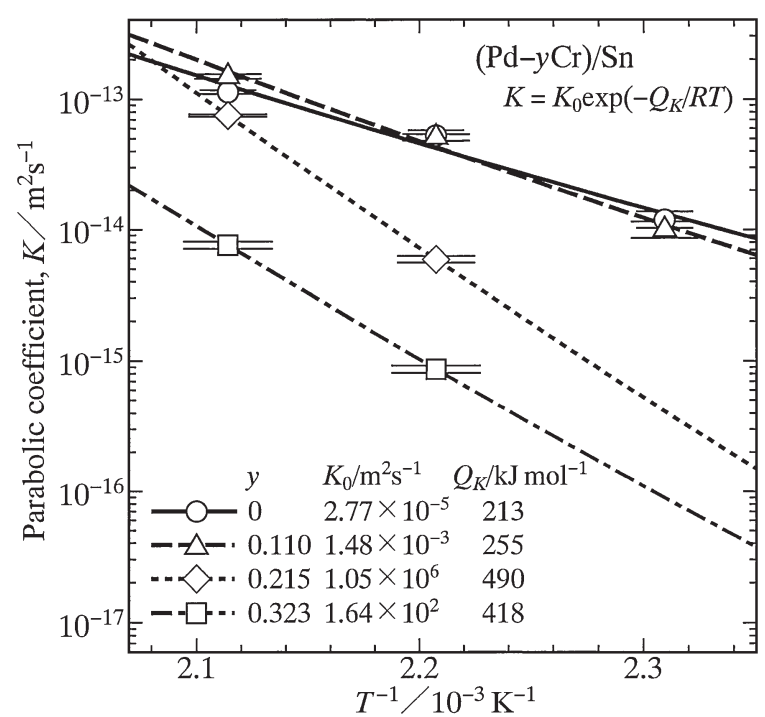

Fig. 12 The logarithm of the parabolic coefficient $K$ versus the reciprocal of the annealing temperature $T$ for $y=0,{ }^{16)} 0.110,0.215$ and 0.323 shown as open circles, triangles, rhombuses and squares, respectively, with error bars.

exception, $K$ was evaluated from the open symbols in Fig. 7 by the least-squares method. The evaluated values of $K$ are plotted against the annealing temperature $T$ as various open symbols with error bars in Fig. 12. In this figure, the ordinate shows the logarithm of $K$, and the abscissa indicates the reciprocal of $T$. Open circles, triangles, rhombuses and squares represent the results of $y=0,{ }^{16)} 0.110,0.215$ and 0.323 , respectively. For $y=0-0.110$, the plotted points are located well on each straight line. Thus, the temperature dependence of $K$ is expressed by the equation

$$
K=K_{0} \exp \left(-\frac{Q_{K}}{R T}\right),
$$


where $K_{0}$ is the pre-exponential factor, $Q_{K}$ is the activation enthalpy, and $R$ is the gas constant. From the open circles and triangles in Fig. 12, $K_{0}$ and $Q_{K}$ were evaluated by the leastsquares method for $y=0$ and 0.110 as shown with solid and dashed lines, respectively. The evaluation gives $Q_{K}=213$ $255 \mathrm{~kJ} / \mathrm{mol}$ for $y=0-0.110$, respectively. Although the value $Q_{K}=255 \mathrm{~kJ} / \mathrm{mol}$ for $y=0.110$ is slightly greater than that $Q_{K}=213 \mathrm{~kJ} / \mathrm{mol}$ for $y=0, K$ takes similar values for $y=0$ 0.110 at $T=433-473 \mathrm{~K}$. As a consequence, it is concluded that $K$ hardly varies depending on $y$ within $y=0-0.110$ at $T=433-473 \mathrm{~K}$. Since the exception was excluded as mentioned above, there are merely two plotted points for $y=0.215-0.323$ in Fig. 12. If the two plotted points are interconnected with each other, $Q_{K}=490-418 \mathrm{~kJ} / \mathrm{mol}$ are obtained for $y=0.215-0.323$, respectively. Although the evaluation of $Q_{K}$ is less reliable for $y=0.215-0.323$ than for $y=0-0.110, Q_{K}$ is almost twice greater for $y=0.215-0.323$ than for $y=0-0.110$. If the interdiffusion coefficients of all the phases in the diffusion couple are known, $K$ is estimated by an appropriate mathematical model. ${ }^{25-32)}$ In such a case, $Q_{K}$ is related to the activation enthalpies of the interdiffusion coefficients. Unfortunately, however, reliable information is not available even for the self-diffusion coefficient of each component in the Cr-rich compounds and the $\mathrm{Pd}-\mathrm{Sn}$ compounds. Nevertheless, the volume fraction of each $\mathrm{Cr}$ rich compound should monotonically increase with increasing value of $y$. Therefore, the large values of $Q_{K}$ for $y=0.215-0.323$ imply that the activation enthalpy of the interdiffusion coefficient is much greater for the $\mathrm{Cr}$-rich compounds than for the $\mathrm{Pd}-\mathrm{Sn}$ compounds.

\section{Conclusions}

The kinetics of the solid-state reactive diffusion in the $(\mathrm{Pd}-\mathrm{Cr}) / \mathrm{Sn}$ system was experimentally examined using the $\mathrm{Sn} /(\mathrm{Pd}-\mathrm{Cr}) / \mathrm{Sn}$ diffusion couples with $\mathrm{Cr}$ mol fractions of $y=0.110,0.215$ and 0.323 . The diffusion couples were isothermally annealed at temperatures of $T=433-473 \mathrm{~K}$ for various periods up to $t=360 \mathrm{~h}$. At the original $(\mathrm{Pd}-\mathrm{Cr}) / \mathrm{Sn}$ interface in the diffusion couple, a compound layer composed of different matrices and lamellar phases is produced due to annealing. The chemical composition of each phase in the compound layer was measured by electron probe microanalysis (EPMA) using the diffusion couples with $y=0.336$ annealed for $t=2100 \mathrm{~h}$ at $T=433-473 \mathrm{~K}$. The EPMA measurement indicates that the matrices are $\mathrm{PdSn}_{2}, \mathrm{PdSn}_{3}$ and $\mathrm{PdSn}_{4}$ from the $\mathrm{Pd}-\mathrm{Cr}$ side to the $\mathrm{Sn}$ side. The $\left(\mathrm{Cr}_{0.9} \mathrm{Pd}_{0.1}\right)_{3} \mathrm{Sn}$ phase is formed as a rather uniform layer at the $(\mathrm{Pd}-\mathrm{Cr}) / \mathrm{PdSn}_{2}$ interface and as coarse flakes in $\mathrm{PdSn}_{3}$. On the other hand, $\mathrm{PdSn}_{4}$ is directly contacted with the $\left(\mathrm{Cr}_{0.95} \mathrm{Pd}_{0.05}\right)_{2} \mathrm{Sn},\left(\mathrm{Cr}_{0.9} \mathrm{Pd}_{0.1}\right) \mathrm{Sn}, \mathrm{CrSn}_{2}$ and $\mathrm{Sn}$ phases. Thus, the following three-phase equilibria appear at $T=433$ $473 \mathrm{~K}$ in the ternary $\mathrm{Sn}-\mathrm{Pd}-\mathrm{Cr}$ system: $\mathrm{PdSn}_{2}+\mathrm{PdSn}_{3}+$ $\left(\mathrm{Cr}_{0.9} \mathrm{Pd}_{0.1}\right)_{3} \mathrm{Sn}, \quad \mathrm{PdSn}_{4}+\left(\mathrm{Cr}_{0.95} \mathrm{Pd}_{0.05}\right)_{2} \mathrm{Sn}+\left(\mathrm{Cr}_{0.9} \mathrm{Pd}_{0.1}\right) \mathrm{Sn}$, $\mathrm{PdSn}_{4}+\left(\mathrm{Cr}_{0.9} \mathrm{Pd}_{0.1}\right) \mathrm{Sn}+\mathrm{CrSn}_{2}$, and $\mathrm{Sn}+\mathrm{PdSn}_{4}+\mathrm{CrSn}_{2}$. The total thickness of the compound layer is proportional to a power function of the annealing time. The exponent of the power function is nearly equal to 0.5 independent of $y$ at $T=453-473 \mathrm{~K}$ and for $y=0-0.110$ at $T=433 \mathrm{~K}$, but becomes $0.7-0.8$ for $y=0.215-0.323$ at $T=433 \mathrm{~K}$. Since grain growth should occur in the compound layer, the exponent close to 0.5 means that the overall compound growth is mostly controlled by volume diffusion. If the exponent is larger than 0.5 , however, the interface reaction at the moving interface contributes to the rate-controlling process. The overall growth rate of the compound layer is not sensitive to $y$ at $y<y_{\mathrm{c}}$, but decreases with increasing value of $y$ at $y>y_{\mathrm{c}}$. Here, the critical composition $y_{\mathrm{c}}$ is 0.1 and 0.2 at $T=433-453 \mathrm{~K}$ and $473 \mathrm{~K}$, respectively. The volume fraction $f$ of the Cr-rich compounds in the compound layer monotonically increases with increasing value of $y$, and the interdiffusion may be slower for the Cr-rich compounds than for the $\mathrm{Pd}-\mathrm{Sn}$ compounds. Thus, the influence of $\mathrm{Cr}$ on the kinetics is attributed to the dependence of $f$ on $y$. Consequently, the addition of $\mathrm{Cr}$ with $y>0.2$ into $\mathrm{Pd}$ effectively inhibits the compound growth during energization heating at the interconnection between a Sn-based solder and a multilayer $\mathrm{Pd} / \mathrm{Ni} / \mathrm{Cu}$ conductor.

\section{Acknowledgements}

The authors are grateful to Mr. K. Sakamoto and Mr. N. Kurokawa at Tyco Electronics AMP Co. Ltd., Japan for stimulating discussions. Thanks are also due to Mr. W. Shinmei with Graduate School at Tokyo Institute of Technology, Japan for assistance in the early stages of the present study. The present study was supported by Tyco Electronics AMP Co. Ltd., Japan. The study was also partially supported by a Grant-in-Aid for Scientific Research from the Ministry of Education, Culture, Sports, Science and Technology of Japan.

\section{REFERENCES}

1) L. Zakraysek: Welding Res. Suppl. Nov. (1972) 536-541.

2) K. N. Tu: Acta Metall. 21 (1973) 347-354

3) M. Onishi and H. Fujibuchi: Trans. JIM 16 (1975) 539-547.

4) H. N. Keller: IEEE Trans. Compon. Hybrids, Manuf. Tech. 2 (1979) 180-195.

5) H. N. Keller and J. M. Morabito: Surf. Interface Anal. 3 (1981) 16-22.

6) J. O. G. Parent, D. D. L. Chung and I. M. Bernstein: J. Mater. Sci. 23 (1988) 2564-2572.

7) A. J. Sunwoo, J. W. Morris, Jr. and G. K. Lucey, Jr.: Metall. Trans. A 23 (1992) 1323-1332.

8) P. T. Vianco, P. F. Hlava and A. L. Kilgo: J. Electron. Mater. 23 (1994) 583-594.

9) D. R. Frear and P. T. Vianco: Metall. Trans. A 25 (1994) 1509-1523.

10) S. Choi, T. R. Bieler, J. P. Lucas and K. N. Subramanian: J. Electron. Mater. 28 (1999) 1209-1215.

11) T. Takenaka, S. Kano, M. Kajihara, N. Kurokawa and K. Sakamoto: Mater. Sci. Eng. A 396 (2005) 115-123.

12) C. Wright: IEEE Trans. Parts Hybrids Packag. 13 (1977) 202-207.

13) H. N. Keller: IEEE Trans. Compon. Hybrids Manuf. Tech. 5 (1982) $408-419$.

14) E. I.-B. Hannech and C. R. Hall: Mater. Sci. Tech. 8 (1992) 817-824.

15) G. Ghosh: Acta Mater. 48 (2000) 3719-3738.

16) T. Takenaka, M. Kajihara, N. Kurokawa and K. Sakamoto: Mater. Sci. Eng. A 406 (2005) 134-141.

17) A. Furuto and M. Kajihara: Mater. Trans. 49 (2008) 294-303.

18) T. Sakama and M. Kajihara: J. Alloy. Compd. 475 (2009) 608-613.

19) T. Sakama and M. Kajihara: Mater. Trans. 50 (2009) 266-274.

20) T. B. Massalski, H. Okamoto, P. R. Subramanian and L. Kacprzak: Binary Alloy Phase Diagrams, (ASM International, Materials Park, $\mathrm{OH}, 1990)$ vol. 2, p. 1311.

21) K. Masui: Master Thesis, Tokyo Inst. Tech., (2010). 
22) K. Motojima, T. Asano, W. Shinmei and M. Kajihara: J. Electron. Mater. 41 (2012) 3292-3302.

23) R. E. Liesegang: Naturw. Wochenschr. 11 (1896) 353-362.

24) K. Osinski, A. W. Vriend, G. F. Bastin and F. J. J. van Loo: Z. Metallkde. 73 (1982) 258-261.

25) M. Kajihara: Acta Mater. 52 (2004) 1193-1200.

26) M. Kajihara: Mater. Sci. Eng. A 403 (2005) 234-240.

27) M. Kajihara: Defect Diffusion Forum 249 (2006) 91-96.

28) M. Kajihara: Mater. Trans. 46 (2005) 2142-2149

29) M. Kajihara: Mater. Trans. 47 (2006) 1480-1484.

30) M. Kajihara and T. Yamashina: J. Mater. Sci. 42 (2007) 2432-2442.

31) M. Kajihara: Mater. Trans. 49 (2008) 715-722.

32) M. Kajihara: J. Mater. Sci. 44 (2009) 2109-2118.
33) M. Hashiba, W. Shinmei and M. Kajihara: J. Electron. Mater. 41 (2012) $32-43$.

34) Y. Muranishi and M. Kajihara: Mater. Sci. Eng. A 404 (2005) 33-41.

35) T. Hayase and M. Kajihara: Mater. Sci. Eng. A 433 (2006) 83-89.

36) K. Mikami and M. Kajihara: J. Mater. Sci. 42 (2007) 8178-8188.

37) M. Kajihara and Y. Tejima: J. Phys. Conf. Ser. 165 (2009) 012091.

38) Y. Tejima, S. Nakamura and M. Kajihara: J. Mater. Sci. 45 (2010) 919_ 928.

39) Y. Yamamoto and M. Kajihara: Mater. Trans. 42 (2001) 1763-1770.

40) Y. Yamamoto and M. Kajihara: J. Electron. Mater. 37 (2008) 17101720 .

41) M. O, Y. Takamatsu and M. Kajihara: Mater. Trans. 55 (2014) 10581064. 